time can be represented in a natural way in twistor space. This interplay between cohomology on complex manifolds and solutions to differential equations on real manifolds is extremely interesting, because it brings together two otherwise unrelated branches of mathematics in an unexpected way. The outstanding application of these ideas to general relativity is the definition of quasi-local quantities which attempts to capture the notion of total energy-momentum and angular momentum associated with the region of space-time enclosed by a topological 2sphere. The current status of this definition and its consequences is described in detail. In addition, several mathematical results on null congruences, on algebraic classification of curvature tensors and on asymptotic structure of space-time at null infinity, which are simplified and illuminated by the use of twistor methods and the spin coefficient techniques, are presented in varying degrees of detail and completeness.

This is primarily a work in mathematics rather than physics. The emphasis is on illustration of the power and elegance of certain techniques rather than on provision of a comprehensive treatment of topics that are of direct application in general relativity. Consequently, the discussion is not uniform; points dealing with twistoral ideas and spin coefficient methods are treated thoroughly, while those requiring ideas from elsewhere are often mentioned only briefly.

Overall, there is a considerable difference between this volume and its companion. Volume 1 (reviewed in Nature $\mathbf{3 1 3}, 607$; 1985) appeared as a finished, definitive work that could be used in courses as well as by individual researchers. Volume 2, on the other hand, has a mixed flavour. Parts of it, such as the treatment of quasi-local mass, report the current state of the art. These parts have the style of lecture notes rather than that of a monograph. Furthermore, none of the chapters has an introductory section to map out the material that follows. Consequently, it is sometimes difficult to see where one is headed, and only those readers who are already familiar with more conventional treatment of topics such as gravitational radiation theory, and energy-momentum and angular momentum in general relativity, will be able to appreciate the simplifications and insights provided by twistor methods. Volume 2 , therefore, is primarily for researchers who want to understand the spirit of twistor theory and for teachers of courses on general relativity who want to broaden their knowledge of the field.

Abhay Ashtekar, a Professor of Physics at Syracuse University, New York, is currently at the Institute of Theoretical Physics, University of California, Santa Barbara, California 93106. USA.

\section{Strategy for future weather}

Nicholas A. Rupke

Climatic Change and World Affairs, Revised Edition. By Crispin Tickell. Center for International Affairs, Harvard University/University Press of America: 1986. Pp.76. \$17.50; pbk \$7.25. Distributed in Britain by Eurospan, 3 Henrietta Street, London WC2E $8 L U$. Hbk £16.55; pbk $£ 7.30$.

ERRATIC blocks and boulders, strewn across much of northern Europe and North America, reminded our ancestors of the waters of the biblical deluge. By around 1840 , the Swiss naturalist Louis Agassiz concluded that these erratics had been put in place by gigantic ice sheets, and were evidence of a former Ice Age.

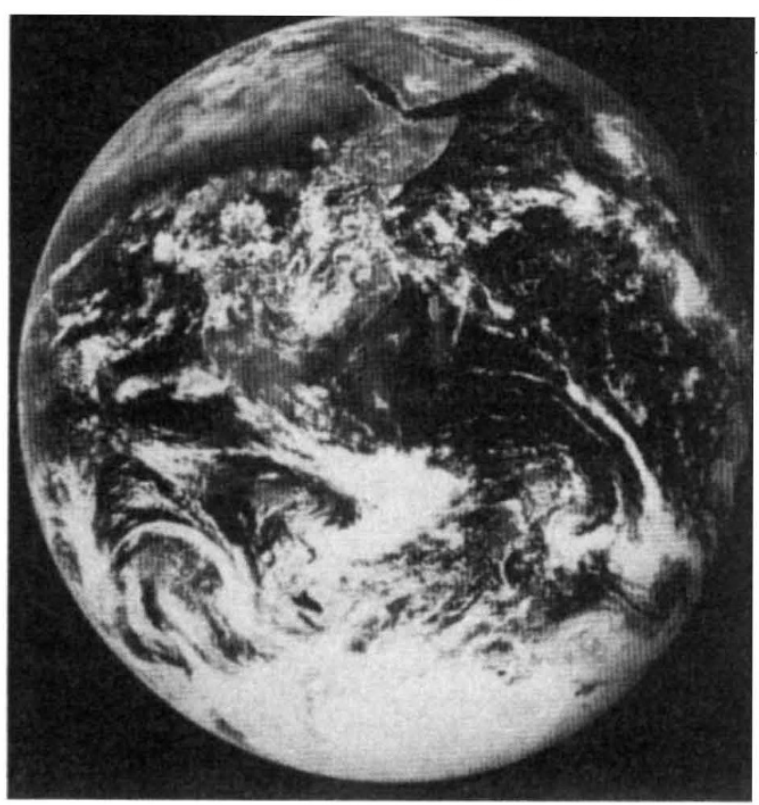

Heavy cloud in the southern hemisphere, as seen from Apollo 17. The photo extends from the Mediterranean to the Antarctic.

great many astronomical and terrestrial factors. Moreover, man himself has become a potentially destabilizing factor as a consequence of large-scale environmental mismanagement, such as the pollution of the air with carbon dioxide, aerosols and other industrial wastes which change the heat balance of our atmosphere.

Much has already been written about the threat to world climate - some authors demonstrating the scientific complexity and uncertainties of the issue, others giving free rein to doomsday predictions of imminent catastrophe in the form of a new and prolonged Arctic winter or, conversely, of the precipitous melting or surging of polar icecaps and a consequent rise in sea level. In this revised edition of a book first published in 1977. Tickell again succeeds in walking the tightrope between these two approaches: he presents an intelligible account of world climate in all its scientific complexity, but does so without letting the reader ose a sense of the reality and potential immediacy of a calamitous deterioration. After all, only a relatively small change of a few degrees Celsius in mean global temperature would suffice to trigger an irreversible feedback process of glacial expanse or retreat at the poles.

The author (who is Permanent Secretary of the Overseas Development Administration in London) has examined the subject with the eyes of both science and international affairs. In a "call for action" he forcefully argues for the need to get some form of international agreement on how to cope with future climatic crises. More specifically, Tickell proposes that administrative responsibility be given to the World Cli-

Thus began the scientific study of glacial climatic change in the geological past change which, during the most recent, Quaternary Period of Earth history, has included half a dozen ice ages alternating with warmer interglacial stages. Simultaneously, however, our awareness of the vast extent of geological time has grown and, as a result, the historic reality of climatic upheaval has receded into the dim distance of "millions of years" before (or after) us.

Crispin Tickell's "brilliant short book" (to quote from Lord Zuckerman's introduction to the British edition) warns us, however, against a false sense of security and an après nous le déluge complacency. Our seemingly stable climate is in fact a vulnerable and changeable product of a mate Program (adopted in 1979 by the World Meteorological Organization) as the custodian of a series of climatic agreements. These should cover all major experiments and actions (industrial and military) which affect the climate. Furthermore, an international code of good climatic behaviour should be adopted and enforced by means of various economic measures.

Beginners and specialists alike will find Climatic Change and World Affairs lucid and stimulating, particularly if they are interested in science policy and international cooperation in the study of weather and climate.

Nicholas A. Rupke is a geologist and an historian of science at Wolfson College, Oxford OX2 6UD, UK 